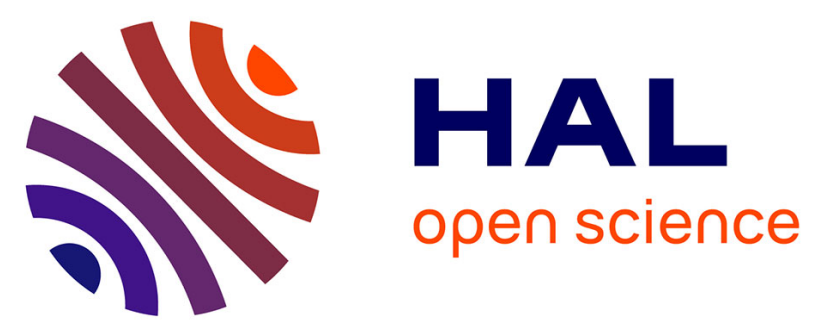

\title{
Middle Iron-Enriched Fructose Diet on Gestational Diabetes Risk and on Oxidative Stress in Offspring Rats.
}

Salam Zein, Farida Sitti, Mireille Osman, Josiane Arnaud, Cécile Batandier, Anne-Sophie Gauchez, Samar Rachidi, Karine Couturier, Isabelle Hininger-Favier

\section{To cite this version:}

Salam Zein, Farida Sitti, Mireille Osman, Josiane Arnaud, Cécile Batandier, et al.. Middle IronEnriched Fructose Diet on Gestational Diabetes Risk and on Oxidative Stress in Offspring Rats.. Biological Trace Element Research, 2016, 175 (2), pp.405-413. 10.1007/s12011-016-0791-3 . inserm01446047

\section{HAL Id: inserm-01446047 https://www.hal.inserm.fr/inserm-01446047}

Submitted on 25 Jan 2017

HAL is a multi-disciplinary open access archive for the deposit and dissemination of scientific research documents, whether they are published or not. The documents may come from teaching and research institutions in France or abroad, or from public or private research centers.
L'archive ouverte pluridisciplinaire HAL, est destinée au dépôt et à la diffusion de documents scientifiques de niveau recherche, publiés ou non, émanant des établissements d'enseignement et de recherche français ou étrangers, des laboratoires publics ou privés. 


\title{
Middle Iron-Enriched Fructose Diet on Gestational Diabetes Risk and on Oxidative Stress in Offspring Rats
}

\author{
Salam Zein ${ }^{1,2} \cdot$ Farida Sitti $^{2,3} \cdot$ Mireille Osman ${ }^{2,4} \cdot$ Josiane Arnaud $^{2,5}$. \\ Cécile Batandier $^{2,4}$ • Anne-Sophie Gauchez ${ }^{5}$ - Samar Rachidi ${ }^{1} \cdot$ Karine Couturier $^{2,4}$. \\ Isabelle Hininger-Favier ${ }^{2,4}$
}

\begin{abstract}
Gestational diabetes mellitus (GDM) is associated with increased insulin resistance and a heightened level of oxidative stress (OS). Additionally, high iron consumption could also increase insulin resistance and OS, which could aggravate GDM risk. The aim of this study is to evaluate a high fructose diet (F) as an alternative experimental model of GDM on rats. We also have evaluated the worst effect of a fructose iron-enriched diet (FI) on glucose tolerance and OS status during pregnancy. Anthropometric parameters, plasma glucose levels, insulin, and lipid profile were assessed after delivery in rats fed an F diet. The effects observed in mothers (hyperglycemia, and hyperlipidemia) and on pups (macrosomia and hypoglycemia) are similar to those observed in women with GDM. Therefore, the fructose diet could be proposed as an experimental model of GDM. In this way, we can compare the effect of an iron-enriched diet on the metabolic and redox status of mother rats and their pups. The mothers' glycemic was similar in the F and FI groups, whereas the glycemic was significantly different in the newborn. In rat pups born to mothers fed on an FI diet, the activities of the antioxidant enzyme glutathione peroxidase (GPx) and
\end{abstract}

Isabelle Hininger Favier

isabelle.hininger@ujf grenoble.fr

1 Clinical Pharmacy Department, Faculty of Pharmacy, Lebanese University, Hadath, Beirut, Lebanon

2 Laboratoire de Bioénergétique Fondamentale et Appliquée_U1050, Université Grenoble Alpes, 38041 Grenoble, France

3 Faculty of Medicine, Universitas Indonesia, Jakarta, Indonesia

4 INSERM U1055, 38041 Grenoble, France

5 Grenoble University Hospital, 38043 Grenoble, France
glutathione-S-transferase in livers and GPx in brains were altered and the gender analysis showed significant differences. Thus, alterations in the glycemic and redox status in newborns suggest that fetuses are more sensitive than their mothers to the effect of an iron-enriched diet in the case of GDM pregnancy. This study proposed a novel experimental model for GDM and provided insights on the effect of a moderate iron intake in adding to the risk of glucose disorder and oxidative damage on newborns.

Keywords Gestational diabetes · Oxidative stress $\cdot$ High fructose diet · Iron

\section{Introduction}

In the field of obstetrics, gestational diabetes mellitus (GDM) is one of most common complications of pregnancy affecting up to $14 \%$ of all pregnancies, depending on the population studied and the diagnostic tests employed [1]. Since GDM is a cause of concern due to increased risks on both mother (e.g., hypertension, preeclampsia, cesarean delivery, and diabetes later in life) and fetus (macrosomia, neonatal hypoglycemia, shoulder dystocia), there is great interest in understanding the etiology and pathophysiological mechanisms of GDM. As the majority of cases return to normal glycemic levels postpartum, GDM has been considered a "transient condition." However, evidence suggests that GDM should be viewed more as a marker for chronic disease as mothers age [2], but it could also predict occurrence of diseases later in life for the newborn [3]. Despite the better diagnosis of GDM and recognition of its adverse consequences for mother and baby in many countries, there is still no consensus regarding the origin of GDM [4]. It is well known that this risk increases with advancing maternal 
age, racial/ethnic disparities, and obesity, but other factors might also be involved [4,5].

It is well documented that GDM is associated with oxidative stress (OS), owing to both overproduction of free radicals and/or a defect in the antioxidant defenses [6-9]. Multiple biochemical pathways and mechanisms of action for glucose toxicity have been suggested [10]; all these pathways have in common the formation of reactive oxygen species (ROS), and they relate to insulin resistance [11].

So far, streptozotocin, an agent of choice for experimental diabetes induction, leading to specific necrosis of the pancreatic $\beta$-cells [12], has been extensively $[13,14]$ used to clarify or to prevent [15] the biochemical mechanisms of GDM. However, this experimental model leads to type 1 diabetes, while the features of GDM are more like a type 2 diabetes (DT2). Therefore, streptozotocin is probably not a good model for GDM [13, 14]. A fructose-rich diet has been used as an experimental model for the study of insulin resistance $[16,17]$ but, so far, not in pregnancy.

Recent studies suggest that iron overload may impair the regulation of body glucose metabolism [18]. A metaanalysis concluded that high iron intake is significantly associated with a greater risk of type 2 diabetes [19]. It is still not clear whether iron leads to the development of GDM, and despite the association between iron intake and GDM risk being examined in several studies [20-24], so far no consensus has been reached [25]. Iron is an essential trace element required for crucial functions of the body, such as oxygen transport and energy production. However, a high iron level increases ROS production, which may cause pancreatic $\beta$-cell dysfunction [26], and insulin resistance and gestational diabetes have been associated with high plasma ferritin and biological evidence of oxidative stress [27].

This study had a dual purpose: to propose the fructose diet as an experimental model for studying GDM and to determine the effects of a moderate iron-enriched fructose diet on the metabolic and OS status of newborns.

\section{Material and Methods}

\section{Animal Care}

All experimental procedure was reviewed and approved by the Joseph Fourier University Institutional Ethic Committee for Animal Experiment. The rats were maintained and handled in agreement with the Guide for the Care and Use of Laboratory Animals. The female Wistar rats (Charles River, L'Arbresle, France), 12 weeks old, were housed in wirebottomed cages in a temperature-controlled room $\left(22{ }^{\circ} \mathrm{C}\right)$, $50 \pm 10 \%$ relative humidity, and a 12 -h light/12-h dark cycle.

\section{Diets}

The diets were purchased from SAFE, 89290 Augis, France. The control group $(\mathrm{C}, n=6)$ was fed by a standard Purina chow. The fructose group received the fructose-rich diet $(\mathrm{F}$, $n=6$ ) containing $65 \%$ of fructose and $12 \mathrm{mg}$ iron/100 g as indicated in Table 1. The fructose iron-enriched diet received the same fructose-rich diet but containing $22 \mathrm{mg}$ iron/100 g $\operatorname{diet}(\mathrm{FI}, n=6$ ) (Table 1). All rats were fed for 4 weeks before mating and during gestation for 3 weeks. The analytical measurement of the iron content of the pellets for the F and FI diet was determined using a quadrupole ICP-MS Thermo X-Series II equipped with collision/reaction cell technology (CCT), quartz impact bead spray chamber, and concentric nebulizer. The Xt interface option was used. The collision reaction gas was a mixture of $\mathrm{He}$ and H2 (97/7). The samples were mineralized in nitric acid and then diluted 100 -fold in water prior to analysis. Fe 56 and $\mathrm{Fe} 54$ were measured and $\mathrm{Ga} 71$ was used as internal standard. An external standard calibration curve was generated using four calibration standards $(0-200-1000$ and $2000 \mathrm{nmol} / \mathrm{l})$. Method accuracy was assessed by analyzing NIST standard reference material $1577 \mathrm{~b}$ (bovine liver) and $\mathrm{ARC} / \mathrm{CL}$ total diet reference material at the beginning and end of the analytical run. The between-run precision was $3.40 \%$ and the bias was $-1.67 \%$.
Table 1 Composition of the diets (g/100 g diet)

\begin{tabular}{lccc}
\hline Composition & Purina chow (group C) & Fructose rich diet (group F) & Fructose iron diet (group FI) \\
\hline Starch & 62 & 0 & 0 \\
Fructose & 0 & 65 & 65 \\
Casein & 22.7 & 20 & 20 \\
Vegetal oils & 4.5 & 5 & 5 \\
Mineral and vitamins & 6,25 & 6,25 & 6,25 \\
Iron mg/100 g diet & 10 & 12 & 22 \\
Cellulose & 4,50 & 5 & 5 \\
$\mathrm{kCal} / 100$ g diet & 379 & 385 & 385 \\
\hline
\end{tabular}




\section{Experimental Procedures}

Eighteen rats are weighed weekly and pups were weighed at delivery. One day after delivery and after overnight fasting, the mothers were anesthetized with sodium pentobarbital intraperitoneally. Some of the mothers were unfertilized which is common figure in animal facilities; therefore, the number of mother with pups was for each group: $\mathrm{C}(n=4), \mathrm{F}(n=5)$, FI $(n=5)$. Blood from mothers was collected by heart puncture in heparinized tubes protected from light and centrifuged at room temperature for $10 \mathrm{~min}$ at $3000 \mathrm{~g}$. Plasma was immediately isolated, aliquoted, and stored at $-80{ }^{\circ} \mathrm{C}$ until analysis. The morning of sacrifice, males and females pups were weighed and decapitated without anesthesia. Blood glucose readings are taken via a drop of blood using a glucometer. Immediately after blood collection, the rats were sacrificed and visceral masses were weighed. Pups' livers and brains were removed, weighed, frozen in liquid nitrogen, and stored at $-80{ }^{\circ} \mathrm{C}$ until analysis. Before analysis, tissue samples were homogeneized (10\%) in buffer (10 mM Tris-base, $1 \mathrm{mM}$ diethylene triamine pentaacetic acid (DPTA)), $1 \mathrm{mM}$ phenylmethanesulfonyl fluoride (PMSF), $\mathrm{pH}=7.4$ ) and centrifuged at $3000 \mathrm{~g}$ and $4{ }^{\circ} \mathrm{C}$ for $10 \mathrm{~min}$.

\section{Biological Parameters}

Fasting glucose, cholesterol, and triglyceride levels were evaluated by enzymatic and colorimetric methods on Roche/Hitachi modular 912 (Roche diagnosis, Meylan, France). Glycemia from pups were assessed using an Accu-Chek ${ }^{\circledR}$ glucometer (Roche Diabetes Care, Meylan, France). Insulin levels were assessed using commercial radioimmunoassay kit (Merck Millipore Corporation, Germany). Insulin sensitivity was calculated using the homeostatic model assessment-insulin resistance (HOMAIR) (formula: fasting glucose $(\mathrm{mg} / \mathrm{dL}) \times$ fasting insulin $\mu \mathrm{UI} / \mathrm{mL} / 405)$. Plasma thiobarbituric acid reactive substance (TBARS) concentrations were assessed as described by Richard et al. [28]. Total plasma antioxidant status was estimated using ferric reducing antioxidant power (FRAP) assay as described by Benzie et al. [29]. Plasma thiol (SH) groups were assayed as described by Faure and Lafond [30]. The reduced (GSH) and oxidized (GSSG) form of glutathione was determined by a kinetic method as prescribed by Akerboom and Sies [31]. Glutathione peroxidase (GPx) activity was evaluated by the modified method of Gunzler et al. [32], using terbutyl hydroperoxide as a substrate instead of hydrogen peroxide. The glutathione-Stransferase (GST) activity was determined by the method of Habig et al. [33].

\section{Statistical Analysis}

Data statistical analyses were performed using the statistical software package (Statistica Program, Statistical Software, Paris, France). Values were expressed as mean \pm standard error of the mean (SEM). Statistical analyses of the data were performed by analysis of variance, using the $t$ test for comparison of the means. Statistical significance was set at $p<0.05$.

\section{Results}

\section{Evaluation of a Fructose Diet as a Model of Gestational Diabetes}

The results of anthropometric and biochemical parameters of mother rats and their offspring are represented in Table 2. A high-fructose diet increased significantly the weight of their pups compared to the control fed group. The weight gain and the visceral fat mass were enhanced but not significantly different between the two groups of mothers. The livers of pups from the $\mathrm{F}$ group were significantly lower than those of the control group, but the brain weight was unaffected by the maternal diet. The results showed that a high-fructose diet increases significantly glycemia, insulin, cholesterol, and triglyceride of mothers, leading to a significant increase in insulin resistance followed by the HOMA test. On the contrary, glycemia of newborns were decreased.

\section{Evaluation of Anthropometric and Oxidative Stress Parameters in Pups and Mothers Fed a Fructose Diet (F) or a Fructose Enriched with an Iron Diet (FI) during Pregnancy}

Although a trend to an increase, the FI diet did not modify significantly the body weight gain during pregnancy, compared to the F fed group (Table 3). In addition, the FI diet had no effect on mothers'glycemia, insulinemia, cholesterol, and triglycerides. However, glycemia and body weight were increased in the pups born of the mothers fed the FI diet and the number of females in the FI group was significantly lower. There are gender differences since the glycemia was significantly increased only in male pups $(p<0.03)$ and the difference of body weight was significant for the female $(p<0.003)$ but almost significant $(p=0.06)$ in male pups.

The results of plasmatic OS parameters of mother rats are represented in Table 4 . No significant difference was found on GPx activity, TBARS, and FRAP between rats fed with $\mathrm{F}$ and FI diet. The oxidative status was also assayed in livers and brains of offspring from the two groups, and results are 
Table 2 Anthropometric and biochemical parameters of mother rats and pups after delivery

\begin{tabular}{lccc}
\hline Parameters & Control & Fructose & $P$ value \\
\hline Weight gain $(\mathrm{g})$ & $17.2 \pm 0.63$ & $21.5 \pm 1.95$ & $P>0.05$ \\
Total visceral fat (g/100 g body weight) & $3.41 \pm 0.53$ & $4.11 \pm 0.35$ & $P>0.05$ \\
Glycemia (mg/dL) & $143 \pm 4.14$ & $163 \pm 3.60^{*}$ & 0.008 \\
Insulin (ng/mL) & $0.58 \pm 0.74$ & $1.96 \pm 0.80^{*}$ & 0.016 \\
HOMA IR(U) & $5.13 \pm 0.75$ & $19.46 \pm 10.71^{*}$ & 0.014 \\
Cholesterol (mg/dL) & $54 \pm 0.01$ & $66 \pm 0.03^{*}$ & 0.05 \\
Triglyceride (mg/dL) & $33 \pm 0.05$ & $88 \pm 0.20^{*}$ & 0.02 \\
Number of pups/dam & $9.5 \pm 2.18$ & $10.0 \pm 2.28$ & $P>0.05$ \\
Male pups/dam & $4.0 \pm 0.58$ & $3.6 \pm 0.81$ & $P>0.05$ \\
Female pups/dam & $5.5 \pm 1.66$ & $6.4 \pm 1.69$ & $P>0.05$ \\
Weight (g) all & $8.5 \pm 0.9$ & $9.5 \pm 1,7^{*}$ & 0.002 \\
Male pups & $8.94 \pm 0.26$ & $10.30 \pm 0.45^{*}$ & 0.03 \\
Female pups & $8.17 \pm 0.2$ & $9.13 \pm 0.26^{*}$ & 0.01 \\
Liver weight all (g/100 g body weight) & $3.54 \pm 0.05$ & $3.02 \pm 0.04^{*}$ & $<0.001$ \\
Male pups & $3.58 \pm 0.09$ & $2.94 \pm 0.07^{*}$ & $<0.001$ \\
Female pups & $3.51 \pm 0.06$ & $3.07 \pm 0.05^{*}$ & $<0.001$ \\
Brain weight all (g/100 g body weight) & $4.14 \pm 0.06$ & $4.12 \pm 0.06$ & $P>0.05$ \\
Male pups & $3.98 \pm 0.07$ & $3.93 \pm 0.1$ & $P>0.05$ \\
Female pups & $4.25 \pm 0.07$ & $4.21 \pm 0.07$ & $P>0.05$ \\
Glycemia (mg/dL) all & $106 \pm 2$ & $78 \pm 2 *$ & $<0.001$ \\
Male pups & $112 \pm 3$ & $74 \pm 3 *$ & $<0.001$ \\
Female pups & $100 \pm 2$ & $81 \pm 2 *$ & $<0.001$ \\
\hline
\end{tabular}

Results were expressed as mean \pm SEM; the number of rats was in the control fed group $(n=4$ mothers and $n=38$ pups) and in the fructose fed group ( $n=5$ mothers and $n=50$ pups ). $* P<0.05$ represented in Tables 5 and 6, respectively. In pups born to mothers in the FI diet group, brain and liver GPx activity was significantly decreased. The gender analysis showed that in the brain, GPx activity was related to a significant decrease in males, while the FI diet has no effect in females. Similarly, we found a gender effect on hepatic GPx, which is decreased in both groups, but the effect was also significant only in females.
Table 3 Anthropometric parameters of mothers and pups fed with an F diet or an FI diet

\begin{tabular}{lccc}
\hline Parameters & \multicolumn{2}{l}{ FI } & $P$ value \\
\hline Mothers weight gain (g) & $21.5 \pm 1.95$ & $27.5 \pm 1.6$ & $P>0.05$ \\
Mothers glycemia (mg/dL) & $16324 \pm 3.6$ & $161.44 \pm 5.76$ & $P>0.05$ \\
Mothers insulinemia (ng/mL) & $1.96 \pm 0.78$ & $1.05 \pm 0.67$ & $P>0.05$ \\
HOMA IR(U) & $19.46 \pm 10.71$ & $10.01 \pm 6.15$ & $P>0.05$ \\
Mothers cholesterol (mg/dL) & $66 \pm 0.03$ & $64 \pm 0.66$ & $P>0.05$ \\
Mothers triglyceride (mg/dL) & $88 \pm 0.20$ & $77 \pm 0.17$ & $P>0.05$ \\
Number of pups/dam & $10,0 \pm 2,3$ & $7.6 \pm 2,2$ & $P>0.05$ \\
Male pups/dam & $3.6 \pm 0.8$ & $3.8 \pm 1.7$ & $P>0.05$ \\
Female pups/dam & $6.4 \pm 1.7$ & $3.8 \pm 0.9 *$ & 0.05 \\
Pups glycemia (mg/dL) All & $78 \pm 1.8$ & $85 \pm 1.8 *$ & 0.02 \\
Male pups & $74.4 \pm 2.77$ & $86.25 \pm 2.52^{*}$ & 0.003 \\
Female pups & $81.13 \pm 2.26$ & $83.18 \pm 2.64$ & $P>0.05$ \\
Pup weight (g) all & $9.3 \pm 0.10$ & $11.0 \pm 0.34^{*}$ & $<0.001$ \\
Male pups & $10 \pm 0.62$ & $11.1 \pm 0.16$ & 0.06 \\
Female pups & $8.9 \pm 0.37$ & $10.9 \pm 0.13^{*}$ & 0.003 \\
\hline
\end{tabular}

Results were expressed as mean $\pm \mathrm{SEM}$; the number of rats was in fructose group (F: $\mathrm{n}=$ mothers and $n=50$ pups $)$ and in fructose iron (FI: $n=5$ mothers and $n=38$ ); $* P<0.05$ 
Table 4 Plasmatic OS parameters in mother rats fed with the F or the FI diet

\begin{tabular}{lcc}
\hline OS parameters of mothers & F $(n=5)$ & FI $(n=5)$ \\
\hline TBARS $(\mu \mathrm{M} / \mathrm{L})$ & $4.6 \pm 0.13$ & $4.03 \pm 0.14$ \\
GPx activity $(\mathrm{U} / \mathrm{L})$ & $6349 \pm 304$ & $6464 \pm 110$ \\
FRAP $(\mu \mathrm{M} / \mathrm{L})$ & $273 \pm 20$ & $284 \pm 25$ \\
$\mathrm{SH}(\mu \mathrm{M} / \mathrm{L})$ & $327 \pm 38$ & $295 \pm 35$ \\
\hline
\end{tabular}

Results were expressed as mean \pm SEM

Even though there was no difference in total hepatic GSH between the two groups, the hepatic GSH concentration was significantly lower in male pups of the FI group but no difference was observed for female pups. The activity of GST was significantly increased in livers of the FI diet group, and the gender analysis showed a significant increase only in males' livers. In the brain, no difference for GSH and GST was observed between groups. There was no significant difference in total antioxidant capacity measured by FRAP assay between the two groups.

\section{Discussion}

Diabetes in pregnant women is associated with increased risk of maternal, fetal, and neonatal complications, which makes GDM a significant public health challenge. Aside from nonmodulating factors of GDM as the mother ages, inadequate nutritional habits, such as high consumption of fructose and iron, might induce oxidative stress and insulin resistance. Therefore, we aimed to assess the fructose diet as a model of diet-induced GDM and then the effect of an iron-enriched fructose diet in inducing metabolic disorder and oxidative stress.

\section{The Fructose Diet as a Model of GDM}

So far, streptozotocin diabetes is the first choice for studying experimental GDM [12] and, to our knowledge, the only model. However, streptozotocin induces specific necrosis of the pancreatic 획-cells, such as type 1 diabetes, rather than insulin-resistant diabetes, and it is still challenging for inducing GDM with streptozotocin [13, 34]. Thus, we evaluated a fructose-rich diet to feed pregnant rats as an experimental animal model for GDM by inducing insulin resistance. Here, the effect of an F diet to induce insulin resistance assessed with the HOMA score during pregnancy was consistent with that obtained with the same F diet in adult rats [35] and with diabetes induced by streptozotocin [36]. Furthermore, in this experimental model, the weight of newborns was significantly larger in the group of mothers fed with the F diet, and this effect is in agreement with the well-documented increased risk of macrosomia in the GDM women [37]. According to the recent guidelines of the Institutes of Medicine, weight gain associated with GDM increases the risk of miscarriages and other adverse outcomes [38], leading to a need for dietary counseling. While the pups were bigger, their blood glucose
Table 5 Liver OS parameters in newborn rats born to rats fed with $\mathrm{F}$ and with FI diet

\begin{tabular}{lccl}
\hline OS parameters & $\begin{array}{l}\text { Group F }(n=50) \\
(18 \text { males; } 32 \text { females })\end{array}$ & $\begin{array}{l}\text { Group FI }(n=38) \\
(19 \text { males; } 19 \text { females })\end{array}$ & $P$ value \\
\hline TBARS $(\mu \mathrm{M} / \mathrm{L})$ & $1.05 \pm 0.2$ & $0.99 \pm 0.2$ & $P>0.05$ \\
Male & $1.12 \pm 0.10$ & $1.05 \pm 0.10$ & $P>0.05$ \\
Female & $0.95 \pm 0.13$ & $0.92 \pm 0.19$ & $P>0.05$ \\
GPx activity $(\mathrm{U} / \mathrm{gP})$ & $254 \pm 7.0$ & $225 \pm 6.6 *$ & 0.03 \\
Male & $253 \pm 15$ & $232 \pm 7.9$ & $P>0.05$ \\
Female & $255 \pm 10$ & $217 \pm 11^{*}$ & 0.005 \\
GSH $(\mu \mathrm{M} / \mathrm{g}$ P) & $636 \pm 57$ & $569 \pm 32$ & $P>0.05$ \\
Male & $711 \pm 73$ & $522 \pm 33^{*}$ & 0.03 \\
Female & $562 \pm 82$ & $625 \pm 52$ & $P>0.05$ \\
GSH/GSSG & $87.79 \pm 6.34$ & $88.87 \pm 4.15$ & $P>0.05$ \\
Male & $83.82 \pm 30.9$ & $87.63 \pm 13$ & $P>0.05$ \\
Female & $82.44 \pm 21.36$ & $91.79 \pm 15.46$ & $P>0.05$ \\
FRAP $(\mu \mathrm{M} / \mathrm{g}$ protein $)$ & $210 \pm 5.8$ & $197 \pm 4.9$ & $P>0.05$ \\
Male & $217 \pm 7.8$ & $201 \pm 6.9$ & $P>0.05$ \\
Female & $202 \pm 8.0$ & $193 \pm 7.0$ & $P>0.05$ \\
GST $(\mathrm{nM} / \mathrm{mg}$ protein $)$ & $232 \pm 5.4$ & $249 \pm 4.3 *$ & 0.015 \\
Male & $228 \pm 8.5$ & $257 \pm 6.9 *$ & 0.02 \\
Female & $236 \pm 7.0$ & $242 \pm 4.0$ & $P>0.05$ \\
\hline
\end{tabular}

Results were expressed as mean $\pm \mathrm{SEM} ; * P \leq 0.05$ 
Table 6 Brain OS parameters in newborn rats born to rats fed with $\mathrm{F}$ and with FI diet

\begin{tabular}{lccc}
\hline OS parameters & $\begin{array}{l}\text { F }(n=50) \\
(18 \text { males; } 32 \text { females })\end{array}$ & $\begin{array}{l}\text { FI }(n=38) \\
(19 \text { males; } 19 \text { females })\end{array}$ & $P$ value \\
\hline GPx activity (U/g protein) & $104,1 \pm 3.8$ & $92,8 \pm 3.5^{*}$ & 0.04 \\
Male & $113 \pm 3.9$ & $91 \pm 2.4 *$ & 0.001 \\
Female & $95 \pm 4.0$ & $95 \pm 8.0$ & $P>0.05$ \\
GSH $(\mu \mathrm{M} / \mathrm{g}$ protein) & $273 \pm 6.4$ & $256 \pm 6.7$ & $P>0.05$ \\
Male & $259 \pm 3.0$ & $250 \pm 6.0$ & $P>0.05$ \\
Female & $301 \pm 6.0$ & $266 \pm 1.4$ & $P>0.05$ \\
GSH/GSSG & $76.08 \pm 7.13$ & $86.47 \pm 11.16$ & $P>0.05$ \\
Male & $7956 \pm 19.54$ & $88.08 \pm 40$ & $P>0.05$ \\
Female & $7055 \pm 19.53$ & $81.25 \pm 24.2$ & $P>0.05$ \\
FRAP $(\mu \mathrm{M} / \mathrm{g}$ protein) & $254 \pm 4.0$ & $253 \pm 4.1$ & $P>0.05$ \\
Male & $258 \pm 3.3$ & $258 \pm 6.5$ & $P>0.05$ \\
Female & $250 \pm 7.3$ & $248 \pm 4.8$ & $P>0.05$ \\
GST (nM/mg protein) & $216 \pm 8.3$ & $228 \pm 5.6$ & $P>0.05$ \\
Male & $213 \pm 36$ & $230 \pm 17$ & $P>0.05$ \\
Female & $213 \pm 27$ & $226 \pm 29$ & $P>0.05$ \\
\hline
\end{tabular}

Results were expressed as mean $\pm \mathrm{SEM} ; * P \leq 0.05$ level was significantly lower than in the control group. This result is also consistent with the fact that the hypoglycemia associated with macrosomia is one of the most common metabolic disorders of the neonate of a GDM mother [37]. It occurs due to the hyperinsulinemia of the fetus in response to the maternal hyperglycemia in utero. The lower liver weight, observed both in male and female pups, could be explained by a decrease in glycogen storage level in response to a state of hepatic insulin resistance [39]. Taken as a whole, our results suggest that the fructose diet could be an alternative successful experimental model for studying GDM.

\section{The Fructose Diet as a Model of GDM}

In the second part of our study, we tested the hypothesis that an increased iron intake would induce metabolic and oxidative disorders during GDM. Iron requirements to meet the fetal pups' needs were estimated at 5-25 mg iron/100 $\mathrm{g}$ diet [40]. In our study, the dose of iron in the FI diet ( $22 \mathrm{mg} / 100 \mathrm{~g}$ diet) corresponded to a moderate, but not too heavy dose, because our goal was to assess the consequences of a high, but not an excessive iron intake, which is rarely the case during pregnancy. Furthermore, our goal was not to confirm the benefit of iron in cases of anemia, but we aimed to evaluate the effect of an iron-rich diet to rats of normal iron status in case of GDM, to increase insulin resistance and OS. Therefore, in the fructose diet, the level of iron was normal. Despite that the FI diet did not induce significant metabolic changes in mothers, the body weights of the newborns were increased and their glycemia was significantly increased. The increase in body weight induced by iron during GDM was more important in female. The number of female progeniture was also smaller in the group of pups born from mothers with a higher iron intake. In a previous study, iron supplementation to pregnant rats was associated to an increased number of placentas without a developing fetus, which could take in part to our result [41]. Since diet gender effects have been reported in offspring born from mothers fed with fructose liquid intake during pregnancy $[42,43]$, we can hypothesize that the FI diet could play a part in the small number of females in the FI diet group. Further experiments are necessary to confirm that this effect is caused by the FI diet.

The FI diet did not affect the oxidative status of the mothers. A previous study [44] in an experimental model of GDM induced by streptozotocin reported an increase in OS induced by intra-peritoneal iron. However, in this study, both the method and the high dose of iron, in contrast to ours, might explain the discrepancies in oxidative stress.

Interestingly, despite the apparently similar OS level between the mothers fed with the F or the FI diet, the redox status of the livers and brains of newborns was altered. This suggests that fetuses were more sensitive to the effect of iron during pregnancy than their mothers.

The GPx activity was decreased both in the liver and the brain of pups born from the FI-fed mothers. The inhibition of GPx activity has often been reported in cases of obesity and insulin resistance [45]. In line of our results, a difference by sex of hepatic GPx activity has also been reported in pups born to diabetic mothers [46]. The decrease in GPx is a common feature of the route toward DT2 [47] and aging [48] and in neurodegenerative diseases [49]. Interestingly, it has been shown that iron supplementation in neonate mice increases the 
risk of Huntington's disease associated with an increased oxidative stress [50] while GPx was neuroprotective in a model of this neurodegenerative disease [51]. Therefore, the GPx decline observed in the brains of the FI males could have important implications for cognitive function. In future studies, it would be interesting to evaluate the consequences of this decrease on their behavior in adulthood.

In our study, males' livers seemed to be more sensitive than those of female to the effect of iron-rich diet. Indeed, the reduced GSH levels of males born to the FI diet-fed mothers served as an iron-induced OS indicator, while in the liver of females, the GSH levels were not modified. In line with this effect, Kim et al. [52] found that iron overload is associated with insulin resistance in men, but not in women. In addition, the GST activity was increased in the liver of pups from the FI group. This would appear to represent an adaptive response to cope with an increased ROS production induced by iron. Indeed, several lines of evidence suggest that GST plays a role in protecting cells from the consequences of such stress, since GST is regulated by ROS such as $\mathrm{H}_{2} \mathrm{O}_{2}$. The induction of GST by ROS has been described as an adaptive response to detoxify some oxidative metabolites produced by OS [53]. GST is a prototypical phase 2 antioxidant enzyme, which has a part in the detoxification of a broad range of toxic and potentially carcinogenic compounds [53]. In accordance with our results, an enhancement of GST was associated with a higher decrease in GPx in iron-treated mice [54]. Also in agreement with our data, suggesting that male might be more sensitive to female to the diet of mothers during pregnancy, a gender effect has been reported with a $10 \%(w / v)$ fructose in drinking water during pregnancy, which increased oxidative stress in the liver of male progenitor but not in female [43]. In this study, in relation with an increased oxidative stress in livers of male offspring, a feature of a metabolic syndrome was observed in male while the females were more resistant. However, it is worth noting that the model of fructose in drinking water is not a model of GDM since it is not associated with glucose impairment [55] during pregnancy. Furthermore, in this study the analyses were performed later after delivery (90 days) while at delivery in our study. Therefore, we cannot exclude that postnatal nutrition could modify metabolic abnormalities induced by iron-fed fetal programming associated with GDM. This deserves further investigation to evaluate later in life the consequences of an oxidative stress in the liver of pups born from mothers with a GDM and with high iron intake.

In conclusion, the similarity in the metabolic and anthropometric effects observed in GDM in women and those of our experimental model allows us to propose the fructose diet as an experimental model of GDM. Clearly, these results indicate that a moderately high iron intake, in the case of GDM, induces adverse effects in the pups (macrosomia and impaired redox status both on the liver and the brain) without significant effects on their mothers. Future studies are warranted to clarify the link between these potential characteristics of a metabolic and oxidative altered state and a possible increased risk of chronic diseases later in life. Proper management of GDM, regarding iron intake in particular, would be of benefit for the newborn's health and the prevention of diseases in adulthood.

Acknowledgments We would like to thank the Rectorat of the Lebanese University, Beirut Lebanon, to support this work.

Compliance with Ethical Standards All experimental procedure was reviewed and approved by the Joseph Fourier University Institutional Ethic Committee for Animal Experiment. The rats were maintained and handled in agreement with the Guide for the Care and Use of Laboratory Animals.

Conflict of Interest The authors declare that they have no conflict of interest.

\section{References}

1. ADA, American Diabetes Association (2003) Position statement. Gestational diabetes mellitus. Diabetes Care 26(Suppl 1):S103 S105

2. Marcinkevagea JA, Narayan KM (2011) Gestational diabetes mellitus: taking it to heart. Prim Care Diabetes 5:81 88

3. Leiva A, Pardo F, Ramírez MA, Farías M, Casanello P, Sobrevia L (2011) Fetoplacental vascular endothelial dysfunction as an early phenomenon in the programming of human adult diseases in sub jects born from gestational diabetes mellitus or obesity in pregnan cy. Exp Diabetes Res. doi:10.1155/2011/349286

4. Harlev A, Wiznitzer A (2010) New insights on glucose pathophys iology in gestational diabetes and insulin resistance. Curr Diab Rep 10:242 247

5. ADA American Diabetes Association (2007) Diagnosis and classi fication of diabetes mellitus. Diabetes Care 30(Suppl 1):42 47

6. Lappas M, Hiden U, Desoye G, Froehlich J, Hauguel de Mouzon S, Jawerbaum A (2011) The role of oxidative stress in the pathophys iology of gestational diabetes mellitus. Antioxid Redox Signal 15: 30613100

7. Zein S, Rachidi S, Hininger Favier I (2014) Is oxidative stress in duced by iron status associated with gestational diabetes mellitus? J Trace Elem Med Biol 28:65 69

8. Gelaleti RB, Damasceno DC, Lima OPH, Salvadori FDM, Calderon IP, Peraçoli JC, Rudge MVC (2015) Oxidative DNA damage in diabetic and mild gestational hyperglycemic pregnant women. Diabetol Metab Syndr. doi:10.1186/1758 599671

9. Shang M, Zhao J, Yang L, Lin L (2015) Oxidative stress and anti oxidant status in women with gestational diabetes mellitus diag nosed by IADPSG criteria. Diabetes Res Clin Pract 109(2):404 410

10. Robertson RP (2004) Chronic oxidative stress as a central mecha nism for glucose toxicity in pancreatic islet beta cells in diabetes. $\mathrm{J}$ Biol Chem 279:42351 42354

11. Houstis N, Rosen ED, Lander ES (2006) Reactive oxygen species have a causal role in multiple forms of insulin resistance. Nature 440(7086):944 948

12. Damasceno DC, Netto AO, Iessi IL, Gallego FQ, Corvino SB, Dallaqua B, Sinzato YK, Bueno A, Calderon IMP, Rudge MVC 
(2014) Streptozotocin induced diabetes models: pathophysiologi cal mechanisms and fetal outcomes. Biomed Res Int. doi:10.1155 /2014/819065

13. Caluwaerts S, Holemans K, Van Bree R, Verhaeghe J, Van Assche FA (2003) Is low dose streptozotocin in rats an adequate model for gestational diabetes mellitus? J Soc Gynecol Investig 10:216 221

14. Kiss A, Lima P, Sinzato Y, Takaku M, Takeno M, Rudge M, Damasceno D (2009) Animal models for clinical and gestational diabetes: maternal and fetal outcomes. Diabetol Metab Syndr. doi:10.1186/1758 5996121

15. Tian ZH, Miao FT, Zhang X, Wang QH, Lei N, Guo LC (2015) Therapeutic effect of okra extract on gestational diabetes mellitus rats induced by streptozotocin. Asian Pac J Trop Med 8(12):1038 1042

16. Busserolles J, Gueux E, Rock E, Demigne C, Mazur A, Rayssiguier Y (2003) Oligofructoseprotects against the hypertriglyceridemic and pro oxidative effects of a high fructose diet in rats. J Nutr 133:1903 1908

17. Kolderup A, Svihus B (2015) Fructose metabolism and relation to atherosclerosis, type 2 diabetes, and obesity. J Nutr Metab. doi:10.1155/2015/823081

18. Hansen JB, Moen IW, Mandrup Poulsen T (2014) Iron: the hard player in diabetes pathophysiology. Acta Physiol 210:717 732

19. Bao W, Rong Y, Rong S, Liu L (2012) Dietary iron intake, body iron stores, and the risk of type 2 diabetes: a systematic review and meta analysis. BMC Med. doi:10.1186/1741 701510119

20. Bo S, Menato G, Villois P, Gambino R, Cassader M, Cotrino I, Cavallo Perin P (2009) Iron supplementation and gestational dia betes in midpregnancy. Am J Obstet Gynecol 201(2):158 e1 6

21. Bowers K, Yeung E, Williams MA, Qi L, Tobias DK, Hu FB, Zhang CL (2011) A prospective study of prepregnancy dietary iron intake and risk for gestational diabetes mellitus. Diabetes Care 34: 15571563

22. Qiu CF, Zhang CL, Gelaye B, Enquobahrie DA, Frederick IO, Williams MA (2011) Gestational diabetes mellitus in relation to maternal dietary heme iron and nonheme iron intake. Diabetes Care 34:1564 1569

23. Fernandez Real JM, Lopez Bermejo A, Ricart W (2002) Cross talk between iron metabolism and diabetes. Diabetes 51:2348 2354

24. Swaminathan S, Fonseca VA, Alam MG, Shah SV (2007) The role of iron in diabetes and its complications. Diabetes Care 30:1926 1933

25. Khambalia AZ, Collins CE, Roberts CL, Morris JM, Powell KL, Tasevski V, Nassar N (2016) Iron deficiency in early pregnancy using serum ferritin and soluble transferrin receptor concentrations are associated with pregnancy and birth outcomes. Eur J Clin Nutr 70(3):358 363

26. Goldstein BJ, Mahadev K, Wu X, Zhu L, Motoshima H (2005) Role of insulin induced reactive oxygen species in the insulin sig naling pathway. Antioxid Redox Signal 7(7 8):1021 1023

27. Casanueva E, Viteri FE (2003) Iron and oxidative stress in preg nancy. J Nutr 133:1700S 1708S

28. Richard MJ, Portal B, Meo J, Coudray C, Hadjian A, Favier A (1992) Malondialdehyde kit evaluated for determining plasma and lipoprotein fractions that react with thiobarbituric acid. Clin Chem 38:704 709

29. Benzie IF, Strain JJ (1996) The ferric reducing ability of plasma (FRAP) as a measure of "antioxidant power": the FRAP assay. Anal Biochem 239:70 76

30. Faure P, Lafond JL (1995) Measurement of plasma sulfhydryl and carbonyl groups as a possible indicator of protein oxydation. In: Favier AE, Cadet J, Kalnyanaraman M, Fontecave M, Pierre JL (eds) Analysis of free radicals in biological systems. Birkäuser, Berlin, pp. 237248
31. Akerboom TP, Sies H (1981) Assay of glutathione, glutathione disulfide, and glutathione mixed disulfides in biological samples. Methods Enzymol 77:373 382

32. Gunzler WA, Kremers H, Flohe L (1974) An improved coupled test procedure for glutathione peroxidase (EC 1.11.1.9.) in blood. Z Klin Chem Klin Biochem 12:444 448

33. Habig WH, Pabst MJ, Jakoby WB (1974) Glutathione S transfer ases. The first enzymatic step in mercapturic acid formation. J Biol Chem 249:7130 7139

34. Goyal SN, Reddy NM, Patil KR, Nakhate KT, Ojha S, Patil CR, Agrawal YO (2016) Challenges and issues with streptozotocin induced diabetes a clinically relevant animal model to understand the diabetes pathogenesis and evaluate therapeutics. Chem Biol Interact 25:244 4963

35. Hininger Favier I, Benaraba R, Coves S, Anderson RA, Roussel AM (2009) Green tea extract decreases oxidative stress and im proves insulin sensitivity in an animal model of insulin resistance, the fructose fed rat. J Am Coll Nutr 28:355 361

36. Damasceno DC, Volpato GT, Calderon IP, Rudge MVC (2002) Oxidative stress and diabetes in pregnant rats. Anim Reprod Sci 72:235 244

37. Kc K, Shakya S, Zhang H (2015) Gestational diabetes mellitus and macrosomia: a literature review. Ann Nutr Metab 66(suppl 2):14 20

38. Harper LM, Tita A, Biggio JR (2015) The institute of medicine guidelines for gestational weight gain after a diagnosis of gestation al diabetes and pregnancy outcomes. Am J Perinatol 32(3):239 246

39. Couturier K, Qin B, Batandier C, Awada M, Hininger Favier I, Canini F, Leverve X, Roussel AM, Anderson RA (2011) Cinnamon increases liver glycogen in an animal model of insulin resistance. Metabolism 60:1590 1597

40. Lin WJ, Kirksey A (1976) Effects of different levels of dietary iron on pregnancy superimposed upon growth in the rat. J Nutr 106: 543554

41. Ward RJ, Wilmet S, Legssyer R, Crichton RR (2003) Iron supple mentation during pregnancy a necessary or toxic supplement ? Bioinorg Chem Appl 1(2):169 176

42. Vilà L, Roglans N, Perna V, Sánchez RM, Vázquez Carrera M, Alegret M, Laguna JC (2011) Liver AMP/ATP ratio and fructokinase expression are related to gender differences in AMPK activity and glucose intolerance in rats ingesting liquid fructose. J Nutr Biochem 22(8):741 751

43. Rodríguez L, Otero P, Panadero MI, Rodrigo S, Álvarez Millán JJ, Bocos C (2015) Maternal fructose intake induces insulin resistance and oxidative stress in male, but not female, offspring. J Nutr Metab 2015 (Article ID 158091):8. doi:10.1155/2015/158091

44. Sampaio AFS, Silva M, Dornas WC, Costa DC, Silva ME, dos Santos RC, de Lima WG, Pedrosa ML (2014) Iron toxicity medi ated by oxidative stress enhances tissue damage in an animal model of diabetes. Biometals 27(2):349 361

45. Kobayashi H, Matsuda M, Fukuhara A, Komuro R, Shimomura I (2009) Dysregulated glutathione metabolism links to impaired in sulin action in adipocytes. Am J Physiol Endocrinol Metab 296: E1326 E1334

46. Kruse MS, Vega MC, Rey M, Coirini H (2014) Sex differences in LXR expression in normal offspring and in rats born to diabetic dams. J Endocrinol. doi:10.1530/JOE 140054

47. Aouacheri O, Saka S, Krim M, Messaadia A, Maidi I (2015) The investigation of the oxidative stress related parameters in type 2 diabetes mellitus. Can J Diabetes 39:44 49

48. De Haan JB, Cristiano F, Iannello RC, Kola I (1995) Cu/Zn superoxide dismutase and glutathione peroxidase during aging. Biochem Mol Biol Int 35:1281 1297

49. Perluigi M, Butterfield DA (2012) Oxidative stress and down syn drome: a route toward Alzheimer like dementia. Curr Gerontol Geriatr Res 72:490 494 
50. Berggren KL, Chen J, Fox J, Miller J, Dodds L, Dugas B, Vargas L, Lothian A, McAllum E, Volitakis I, Roberts B, Bush AI, Fox JH (2015) Neonatal iron supplementation potentiates oxidative stress, energetic dysfunction and neurodegeneration in the R6/2 mouse model of Huntington's disease. Redox Biol 4:363 374

51. Mason RP, Casu M, Butler N, Breda C, Campesan S, Clapp J, Green EW, Dhulkhed D, Kyriacou CP, Giorgini F (2013) Glutathione peroxidase activity is neuroprotective in models of Huntington's disease. Nat Genet 45:1249 1254

52. Kim CH, Kim HK, Bae SJ, Park JY, Lee KU (2011) Association of elevated serum ferritin concentration with insulin resistance and impaired glucose metabolism in Korean men and women. Metabolism 60(3):414 420
53. Hayes JD, Pulford DJ (1995) The glutathione S transferase super gene family: regulation of GST and the contribution of the isoen zymes to cancer chemoprotection and drug resistance. Crit Rev Biochem Mol Biol 30(6):445 600

54. Madra S, Mann F, Francis JE, Manson MM, Smith AG (1996) Modulation by iron of hepatic microsomal and nuclear cytochrome $\mathrm{P} 450$, and cytosolic glutathione $\mathrm{S}$ transferase and peroxidase in C57BL/10ScSn mice induced with polychlorinated biphenyls (Aroclor 1254). Toxicol Appl Pharmacol 136(1):79 86

55. Rodríguez L, Panadero MI, Roglans N, Otero P, Álvarez Millán JJ, Laguna JC, Bocos C (2013) Fructose during pregnancy affects ma ternal and fetal leptin signaling. J Nutr Biochem 24(10):1709 1716 